\section{CARTOGRAFIA SOCIAL, TERRA E TERRITÓRIO}

Henri Acselrad (Org.)

Rio de Janeiro: IPPUR/UFRJ, 2013

Coleção Território, Ambiente e Conflitos Sociais

Carolina Ferreira da Fonseca

Graduada em Decoração pela Universidade Federal de

Uberlândia (UFU); mestre e doutoranda em Arquitetura e Urbanismo pela Universidade Federal da Bahia (UFBA), Brasil.

E-mail: caca.fonseca@gmail.com.

Cartografia social, terra e território é o terceiro título da coleção Território, Ambiente e Conflitos Sociais, pautada por pesquisas do Laboratório Estado, Trabalho, Território e Natureza (ETTERN), do Instituto de Pesquisa e Planejamento Urbano e Regional da Universidade Federal do Rio de Janeiro (IPPUR/ UFRJ). Uma coleção-observatório dos debates em torno das tramas territoriais e dos modos como a prática cartográfica vem redefinindo os engendramentos espaciais e sociais contemporâneos. $\mathrm{Na}$ abertura do livro, Henri Acselrad expóe um conjunto de mapas sobre a "Distribuição espacial das experiências de mapeamento" realizadas no Brasil entre 1992 e 2012 . Uma miríade de marcadores passam a povoar a figuração do território brasileiro e desvelam de forma panorâmica a emergência da cartografia social, enquanto um campo em construção, há aproximadamente 15 anos. A apresentação do livro revela a envergadura sociológica dos processos mobilizados nesse ínterim e, ao percorrer a obra, observa-se a polifonia das narrativas pelas vozes de sujeitos da terra e do território, de teóricos e de representantes políticos - o que constitui a face antropológica de algumas das 284 experiências identificadas pelo projeto de pesquisa "Experiências em cartografia social e mapeamento participativo".

Os capítulos do livro traçam um quadro relacional de consistente substrato histórico e etnográfico das tensóes centrais nas disputas entre terra e território, seus sentidos, inserções políticas, emergências conceituais e abordagens críticas. Um conjunto de relaçóes tecidas especialmente no campo das Ciências Sociais e as suas intercorrências nas possibilidades de representação, ação e construção política dos sujeitos que disputam tanto terra quanto território nas tramas expansionistas e desenvolvimentistas do capitalismo contemporâneo rumo ao campo.

Nas palavras do organizador: "É nesse contexto que o presente livro procura estruturar sua discussão, reunindo elementos que nos permitam melhor entender como se deu e se dá empiricamente - e como se pensou/se pensa teoricamente - a linha de demarcaçáo estabelecida entre camponeses, de um lado, e índios/remanescentes de quilombolas/extrativistas, de outro, assim como as linhas de passagem - histórica e estrategicamente construídas - entre identidades e reinvindicaçóes respectivas por terra e território, entre lutas por distribuição da terra e lutas por reconhecimento de direitos territoriais, de cuja articulação depende, por certo, o próprio processo de democratização da sociedade brasileira." (ACSELRAD, 2013, p. 13-14)

Estas linhas de demarcação e linhas de passagem sugeridas por Acselrad são os eixos estruturantes das argumentações reunidas no livro. Percorre-se um extenso repertório etnográfico, distribuído em localidades do Pará, Amazonas, Mato Grosso do Sul, Tocantins e do Nordeste, mais especificamente na dimensão de fronteira deflagrada pelos processos aí analisados, envolvendo quebradeiras de coco, ribeirinhos do Rio Sáo Francisco e da bacia do Alto Uruguai, indígenas de inúmeras etnias, seringueiros, quilombolas, castanheiros, garimpeiros, posseiros de múltiplas procedências, criadores de gado, grandes fazendeiros agropecuários, madeireiros, sojicultores, mineradoras, etc. Uma complexa trama de sujeitos enredados politicamente em funçáo de mega projetos mobilizados pelo bloco hegemônico do capitalismo contemporâneo, como as Hidrelétricas de Sobradinho, Itá, Machadinho e Tucuruí, o Gasoduto Brasil-Bolívia (Gasbol), o contexto Pró-Álcool, a transposição do Rio São Francisco, o Complexo Industrial e Portuário do Pecém; além de tangenciar outros extemporâneos, como a Expedição Roncador-Xingu, a Fundação Brasil-Central, a Rodovia Belém-Brasília, a BR-262, etc.

A cada capítulo agregam-se novas dimensôes aos povos, comunidades e sujeitos coletivos agrupados pela insígnia de tradicionais e/ou originários e suas implicaçôes com a identidade do camponês. São singularidades cuja caracterização, situação e modo de ação política engendram impasses pertinentes 
para se refletir sobre as formas de ocupação, acesso e apropriaçáo do espaço rural. Uma intrincada composição de forças emerge do confronto entre o bloco hegemônico do capitalismo, delineado por agentes do capital agroindustrial, mínero-metalúrgico, energético-empreiteiro e financeiro, e um aglomerado múltiplo, cindido teórica e empiricamente em duas classificaçôes de sujeitos: camponeses e povos tradicionais. O questionamento de Boaventura de Sousa Santos (2003, p. 25) evocado no livro escancara o paradoxo destes impasses e acena, noutros termos, para interaçôes entre as tais linhas de demarcação e linhas de passagens: "como compatibilizar a reinvindicação de uma diferença enquanto coletivo e, ao mesmo tempo, combater as relaçóes de desigualdade e de opressáo que se constituíram acompanhando essa diferença?”.

Diante do paradoxo, um quadro analítico é traçado a partir de abordagens definidas como Antropologia dos Grandes Projetos, Antropologia Econômica e Antropologia da Territorialidade, formulaçôes tributárias das seguintes hipóteses recorrentes na obra: 1) as lutas sociais são lutas territoriais; e 2) o território é o elemento condensador de direitos e, portanto, trata-se da plataforma primordial nas experiências emancipatórias. Este diálogo entre Antropologia e Sociologia, mediado pelas derivaçóes citadas acima, testemunha um esforço analítico e empírico absolutamente relevante para compreender as passagens entre território e terra, cultura e trabalho e reconhecimento e redistribuição, na direção do desafio proposto por Sousa Santos (2003): como desatar desigualdade e diferença?

Para entender as especificidades de terra e território, André Dumans Guedes expóe os sentidos analíticos em que ora se manifesta a proeminência antropológica, ora a economicista. $\mathrm{O}$ esforço do autor é de "matizar aquelas análises que identificam de maneira reducionista a 'terra' a fatores econômicos, tentando mostrar, que a problemática camponesa não se encontrava desvinculada da discussão de aspectos 'culturais'. [...] Num movimento simétrico e inverso ao realizado nesse texto, poderíamos então nos perguntar como se coloca analiticamente o tema do 'trabalho' nestes universos em que estáo (e são) situadas as comunidades tradicionais." (GUEDES, 2013, p. 73).

A rejeição à associação simplista e unilateral entre terra $\mathrm{x}$ trabalho e território $\mathrm{x}$ cultura persiste entre os demais autores. Esboça-se pela perspectiva de Andrey Cordeiro Ferreira um contraponto à oposição entre Economia Política e Antropologia, na direção de uma leitura dialética entre Política e Economia, considerando a historicidade de distintas lógicas econômicas. $\mathrm{O}$ autor estabelece uma leitura diagonal entre as escalas macro (histórico-universal) e micro (concreta particular) e delineia permeabilidades no choque entre diferentes lógicas e racionalidades, mais pontualmente entre a lógica da reciprocidade e a da redistribuição, diante da "política dos caciques" empreendida na expansão e estruturação da agroindústria canavieira. Por este viés, Valter do Carmo Cruz argumenta sobre o alargamento da contestação política e alerta para os reducionismos dos paradigmas economicistas e também para o risco da reificação da cultura, do separatismo e da clausura entre os grupos, quando a política de reconhecimento torna-se sinônimo de parâmetros identitários. E novamente a questão de Sousa Santos (2003) desafia as abordagens aqui colocadas.

O livro coloca em evidência como os cientistas sociais orientam politicamente tais contextos, na medida em que, ao tratar da concepçáo dos povos que estudam, acionam categorias como classe, sociedade nacional, cultura tradicional, etnicidade e status; além de processos como subordinação, resistência, colapso, assimilação, encontro, fricção interétnica, situação (de fronteira, de classe e étnica), politização, sinergia, territorialização, desterritorialização, impacto, efeito, entre outros. Todos estes processos e categorias são convergentes com a discussão de conflito, deflagrada com os movimentos de ocupação territorial e a consolidação do regime fundiário do país, mais pontualmente nos limiares das fronteiras das propriedades em disputa.

A seguinte afirmação proposta por Guedes (2013, p. 69, grifos nossos) explicita de forma bastante sucinta um eixo transversal que perpassa diversas abordagens do livro: "[...] nos anos 80 os 'estudos sobre comunidades rurais que apresentavam a particularidade de serem negras' logo cedem lugar àqueles centrados nas 'comunidades negras que tinham a particularidade de serem camponesas'”. Esta alteração de relevo entre as dimensôes grifadas coloca-se central na discussão sobre os processos de redistribuiçấo de terras e de reconhecimento de territórios, e evidencia a perspectiva epistemológica e ontológica 
da obra, que procura entender como se constituem os sujeitos sociais destas demandas, tanto no campo analítico como na ação política.

A nova gramática das lutas sociais proposta por Cruz indaga tais dimensóes, na tentativa de compreender como se dá a passagem de "velhos agentes" para "novos sujeitos" políticos ou "novas-posiçóesde-sujeito", decorrente da politização das nomeações da vida cotidiana. As lutas ensejadas pelas águas, reflexão proposta por Ana Maria Daou (2013, p. 84, grifo nosso), aponta uma constatação: “(...) a definição de quem são os atingidos é certamente um dos objetos de disputa, referindo-se à capacidade de se fazer ver e, assim, de impor uma divisáo do mundo social". Destas associaçooes, resultam as intercorrências entre luta política e epistêmica.

A politização define-se como disputa por visibilidade e posição, atrelada neste processo às nomeaçôes da vida cotidiana. Estes elos são explorados mediante as formulaçóes de Fraser (2009, p. 150-151), que encara a representaçáo como "o 'estabelecimento de fronteiras do político' [...], a constituição das 'fronteiras da comunidade política' implicando sistemas classificatórios que incluem e excluem, definindo quem pertence ou não e quem, portanto, tem ou não direitos." Por este ângulo, alinha-se uma colocação de Guedes (2013, p. 70, grifos nossos): “a organizaçáo social das diferenças perante outros grupos e a sociedade mais ampla e via a seleçáo e politizaçáo de certos traços e aspectos particulares, é um fator mais importante na formaçáo dos grupos [...] do que os conteúdos culturais em si mesmos." Atrelam-se, portanto, posição, divisão, seleção, classificação e organização como constituintes dos sujeitos em questão. Trata-se de uma disputa incessante entre pertencimento, direito e representação no rol dos conflitos em torno das cosmografias vigentes e instituintes.

A emergência da elaboração analítica frente às deflagrações empíricas demarca a postura inicial proposta por Acselrad, ao sobrepor as demarcaçóes e as passagens como linhas de interesse para compreender a complexidade das relaçóes de forças mobilizadas em torno da redistribuição da terra e do reconhecimento dos territórios. Enquanto estratégia de representação política, alguns autores recorrem ao reclame de Almeida (2007), que reivindica um culturalismo agrário como forma de constituir uma arma política para a reivindicação de direitos fundiários, jurídicos, educacionais e de outros dos quais são destituídos os camponeses, aqueles que "[...] se encontram amplamente desprovidos da capacidade de delinear sua própria identidade" (ROMANO, 1988, p. 14).

Tais indicações contrapõem-se à predominância, verificada por Daou, do "desaparecimento social" e da "morte" do camponês/campesinato brasileiro, um tipo de fatalismo despotencializador das singularidades passíveis de colaborar na constituição destes novos-velhos-sujeitos políticos. Observa-se a recorrência da "ideologia do desaparecimento" no contexto dos povos indígenas do Nordeste, problematizado por $\mathrm{Al}$ zení de Freitas Tomaz, Juliana Neves Barros e Juracy Marques. As autoras retomam criticamente o contexto de invenção do sujeito "caboclo" e apontam para uma estratégia de apagamento da especificidade indígena pelo suposto processo de mistura e integração. Entretanto, ao afirmarem o incessante movimento político dessas construçôes, alertam para a potência da ressignificação das identidades mais reacionárias: "processos de nomeação, de atribuição e autoatribuição não são estanques nem cristalizados, são estruturados dentro das dinâmicas político-organizativas dos grupos e mesmo termos como 'caboclo' podem ser acionados como modos de afirmação." (TOMAZ; BARROS; MARQUES, 2013, p. 281)

Ao embrenharem-se Brasil adentro, guiados principalmente pelas frentes pioneiras e de expansão, os autores colocam em relevo mecanismos fundantes da própria definição do território nacional e do regime fundiário do país: a operância hegemônica da propriedade privada e da titulação individual em contraponto às experiências mais recentes de titulação coletiva e constituição do bem comum. Nessa incursão, acabam por problematizar como atuam diversas dimensões, instâncias e instituições do Estado, circunscritas pela agenda neoliberal, como Incra, Funai, Eletrobrás, Ministério da Integração, Congresso Nacional, Supremo Tribunal Federal, Ibama, Procuradorias Públicas de vários estados, Interba (Instituto de Terras da Bahia), Interpa (Instituto de Terras do Pará), prefeituras, entre outros.

Wendell Ficher Teixeira Assis (2013, p. 203) aprofunda no processo de perda substantiva do valor produtivo da terra frente à ascensão do valor especulativo e perscruta a posição do Estado perante 
as estratégias do bloco hegemônico a respeito da titulação da propriedade: "Uma demanda por terra não desafia, necessariamente, as regras e regulações com que se administra o direito à propriedade, ao passo que uma demanda territorial evoca questóes de poder, de afirmação de identidade, de autogestão e controle dos recursos naturais, procurando impor uma territorialização que, no interior do espaço nacional, é fundamentada na cidadania territorial." Entretanto, o autor constata como o próprio Estado marginaliza o uso comum - enquanto entidade capaz de regular a estrutura agrária brasileira noutros termos - ao colocar impasses burocráticoadministrativos e entraves políticos para a titulação coletiva e a demarcação de território. Ou seja, ele mesmo induz a incorporação de terras públicas nos circuitos de acumulação do capital e o avanço do regime de propriedade privada.

Numa constatação correlata, Edwin Muñoz Gaviria (2013, p. 239) aponta o Estado como facilitador da competitividade dos territórios, mediador social do desenvolvimento e viabilizador $\mathrm{da}$ agenda neoliberal diante das "[...] suas estratégias de mercantilização e privatização da terra; expulsão de comunidades tradicionais; conversão de formas diversas de direitos de propriedade comunal, coletiva e estatal para direitos exclusivos de propriedade privada e a flexibilização das normas de regulação de modo a favorecer a rentabilidade dos investimentos."

A coimplicação fronteira-conflito é retomada em diversos pontos do livro, em que se interpóem inúmeras figuras jurídicas acionadas para a efetivação dos regimes de propriedade em jogo (familiar, individual, coletiva). Titulação, posse, uso, concessão, domínio e reserva são artefatos jurídicos absolutamente centrais no confronto declarado entre o bloco hegemônico - e seu respectivo regime de propriedade - e os sujeitos-políticos, cuja cosmografia converte-se em obstáculo à realização de seus projetos. Nessa arena, vem à tona os modos como tais sujeitos e o referido bloco apropriam-se de instrumentos como a Constituição Federal de 1988, o Estatuto da Terra, as Leis de Terra de 1850, o Programa Terra Legal, a Convençáo 169 da OIT e a Declaração da ONU, no sentido de legitimar suas posiçóes. A própria cartografia social passa a integrar tais instrumentos jurídicos e a amplificar os "trunfos do poder" (RAFFESTIN, 1993), numa conjuntura declaradamente assimétrica.

Nessa perspectiva, ao se depararem com o impasse entre os povos indígenas do Nordeste e a transposição do Rio São Francisco, Tomás, Barros e Marques discutem sobre a legalização de distintas formas de expressão territorial. A partir da virada étnicoterritorial, persiste a questáo de como incorporar outros padróes narrativos às cartografias, no sentido de enfrentar a razão hegemônica e instrumental do Estado sobre o território. Os autores alinham-se aos apontamentos de Little (2002), para quem "a historicidade desses territórios é complementada pela historicidade dos conceitos que são utilizados para entendê-los e enquadrá-los, surgindo uma espécie de convergência entre os conceitos jurídicos, políticos e etnográficos, os três formando parte de um mesmo processo de constituição e resistência dessas comunidades."

Um traço singular da obra é seu caráter polifônico, ressonante dos novos e múltiplos agenciamentos sociopolíticos mobilizados pela disputa dos direitos por terra e território, operados a partir de diferentes formas de associativismo, comunitarismo, redes, unidades de mobilização, organizações solidárias e populares e cooperativas. Formaçôes muitas vezes tomadas como inconciliáveis, mas alinhadas estrategicamente a fim de confrontar a contundência da dominação, da colonialidade e do imperialismo, desencadeada pelos projetos em questão.

Cartografia social, terra e território apresenta-se, portanto, como um livro condensador do debate epistemológico, ontológico e metodológico no âmbito das Ciências Sociais, detido sobre os seguintes termos: terra e território; trabalho e cultura; distribuição e reconhecimento; e direitos universais e diferenciados. Um livro-observatório das incessantes tensóes desencadeadas teórica e politicamente entre tais termos e dos traçados territoriais emergentes com a intensificaçáo das experiências de cartografia social no Brasil profundo. Um livro-parlatório povoado de vozes enunciadas por sujeitos cujos contornos evidenciam a face da "alteridade mortal" presente nos "confins do humano" (MARTINS, 1997) e engajadas nas lutas por terra e território Brasil adentro. Por fim, um livro-provocaçáo aos pensadores remetidos ao campo das Ciências Sociais, acirrando 
um exercício insistente quanto aos posicionamentos assumidos, uma vez que constituem peça fundamental na turbulenta guerra dos mapas.

\section{REFERÊNCIAS BIBLIOGRÁFICAS}

ALMEIDA, M. Narrativas Agrárias e a morte do campesinato. Ruris - Revista do Centro de Estudos Rurais, Campinas, v.1, n. 2, p. 157-186, set. 2007.

FRASER, N. Reenquadrando a justiça em um mundo globalizado. Lua nova, São Paulo, n. 77, p. 11-39, 2009. LITTLE, P. Territórios sociais e povos tradicionais no Brasil: por uma antropologia da territorialidade. Série Antropologia, Brasília, n. 322, 2002.

MARTINS, J. S. A Fronteira: a degradação do outro nos confins do humano. 1997

RAFFESTIN, C. Por uma geografia do poder. São Paulo: Ática, 1993

ROMANO, J. Discursos e Movimentos. O efeito da teoria e a ação política dos trabalhadores do sul do Brasil. Mimeo. Rio de Janeiro: Museu Nacional, 1988.

SOUSA SANTOS, B. Reconhecer para libertar: os caminhos do cosmopolitismo multicultural. Rio de Janeiro: Civilização Brasiliense, 2003.

\section{REBEL CITIES: FROM THE RIGHT TO THE CITY TO THE URBAN REVOLUTION}

David Harvey

New York: Verso, 2012

Raul da Silva Ventura Neto

Graduado e mestre em Arquitetura e Urbanismo pela Universidade Federal do Pará (UFPA); doutorando em Desenvolvimento Econômico pela Universidade Estadual de Campinas (UNICAMP), Brasil. E-mail: raulvneto@hotmail.com.

Autor de obras seminais da crítica marxista sobre a produçáo social do espaço urbano no capitalismo, pode-se dizer que David Harvey - ao menos no Brasil - dispensa apresentaçóes. Isso porque as hipóteses e reflexôes contidas em trabalhos como $A$ Justiça Social e a Cidade, A Produção Capitalista do
Espaço, Os Limites do Capital e Condição Pós-moderna, para citar somente alguns, tornaram-se, em grande medida, marcos teóricos obrigatórios de acadêmicos que se dedicam à pesquisa da questáo regional e urbana no Brasil.

No seu mais recente trabalho - Rebel Cities: from the right to the city to the urban revolution -, Harvey deixa ainda mais evidente seu rigor metodológico com o pensamento e as categorias propostas por Marx, todavia sem deixar amarrarse por seus limites históricos. Segue, como objetivo central da sua pesquisa, a compreensão do capitalismo contemporâneo através - mas não somente - do desnudamento das estruturas que definem o processo de urbanização alçadas, em Rebel Cities, à posição de componente indispensável ao entendimento das contradiçóes atuais, que imanam do próprio sistema.

Ao longo do livro, Harvey apresenta hipóteses interpretativas para os levantes urbanos recentes, como os da Primavera Árabe, os indignados na Espanha, os da praça Syntagma em Atenas, entre outros. O trabalho está divido em duas seçôes, The Right to the City e Rebel Cities, com um total de sete capítulos. Os cinco primeiros capítulos foram originalmente publicados pelo autor na forma de artigos em periódicos acadêmicos, entre os anos de 2002 e 2011, sofrendo leves modificaçóes para a nova publicação, de forma a assegurar a unidade do trabalho.

No prefácio (inédito até então), Harvey apresenta as hipóteses centrais do livro, partindo de uma ampla resenha de fundamentos conceituais de Lefebvre sobre Direito à Cidade. Destaca, particularmente, o entendimento de Direito à Cidade enquanto um clamor resultante da dor existencial do dia a dia urbano e uma demanda que leva ao enfrentamento dessa insatisfação, reivindicando-se, assim, uma vida urbana alternativa: menos alienada, mais significativa e lúdica. $\mathrm{O}$ modo como o Direito à Cidade tende a ser reivindicado nos termos de Lefebvre pode, para Harvey, proporcionar um modelo de inspiração que explique o clamor e as demandas contidas nos protestos urbanos recentes.

É por isso que recupera uma importante ideia de Lefebvre. Movimentos revolucionários frequentemente (se não sempre) assumem uma di- 